\title{
Diagnosis and Therapeutic Aspects of the Ileo-Sigmoidian Node in the General Surgery Department of Gabriel Toure Chu
}

\author{
Maïga Amadou ${ }^{*}$, Diakité Ibrahima², Bah Amadou², Diallo Aly Boubacar'1, Traoré Bathio1, \\ Moussa Diassana1, Sidibé Boubacar Yoro², Koné Tani2 ${ }^{2}$, Doumbia Arouna Adama², \\ Traoré Amadou' ${ }^{2}$, Saye Zakari², Diallo Mamadou ${ }^{3}$, Konaté Moussa ${ }^{3}$, Saadé Oumou Hélène², \\ Kanté Lassana ${ }^{2}$, Konaté Madiassa ${ }^{2}$, Dembélé Souleymane ${ }^{2}$, Samaké Moussa², \\ Dembélé Bakary Tientigui², Traoré Alhassane ${ }^{2}$, Togo Adégné ${ }^{2}$
}

${ }^{1}$ General Surgery Department, University Hospital, Bamako, Mali

${ }^{2}$ General Surgery Department, Sikasso Hospital, Sikasso, Mali

${ }^{3}$ Reference Center of Commune VI, Bamako, Mali

Email: *amadoumaiga3@gmail.com

How to cite this paper: Amadou, M., Ibrahima, D., Amadou, B., Boubacar, D.A., Bathio, T., Diassana, M., Yoro, S.B., Tani, K., Adama, D.A., Amadou, T., Zakari, S., Mamadou, D., Moussa, K., Hélène, S.O., Lassana, K., Madiassa, K., Souleymane, D., Moussa, S., Tientigui, D.B., Alhassane, T. and Adégné, T. (2022) Diagnosis and Therapeutic Aspects of the Ileo-Sigmoidian Node in the General Surgery Department of Gabriel Toure Chu. Surgical Science, 13, 23-27.

https://doi.org/10.4236/ss.2022.131004

Received: November 12, 2021

Accepted: January 14, 2022

Published: January 17, 2022

Copyright $\odot 2022$ by author(s) and Scientific Research Publishing Inc. This work is licensed under the Creative Commons Attribution International License (CC BY 4.0).

http://creativecommons.org/licenses/by/4.0/

\begin{abstract}
Introduction: Emergency medico-surgical ileosigmoid node is a rare cause of intestinal obstruction. Diagnosis and treatment must be prompt. Objective: To determine the frequency of NIS, to describe the diagnostic aspects, therapeutic aspects and to analyze the postoperative effects. Methodology: Retrospective and prospective study from January 2006 to December 2020 including all patients operated on for ileosigmoid node confirmed by the intraoperative diagnosis at the CHU Gabriel Touré. Results: From January 2006 to December 2020 (15 years), 30 cases of ileo-sigmoid node were recorded in the service. During this period NIS accounted for $0.19 \%$ of surgeries. Abdominal pain was present in (100\%) of cases, vomiting was present in $80 \%$ and cessation of materials and gas (57\%). All of our patients underwent ASP and CT (1 case). All of our patients were operated on, and exploration revealed intestinal necrosis in $97 \%$. The surgical procedures performed were colostomy according to HARTMANN (63\%), anastomosis resection (16\%), devolvulation (10\%). Restoration of continuity was achieved in (73\%). The postoperative consequences were straightforward in (80\%). Morbidity was $17 \%$ including infection of the lining. Mortality was 3\% (1 case). Conclusion: NIS is an emergency, the diagnosis and the management must be fast and precise.
\end{abstract}

\section{Keywords}

Ileosigmoid Node, Digestive Surgery, Bamako, Mali 


\section{Introduction}

The ileosigmoid node (NIS) or double ileosigmoid volvulus is a winding of the small intestine around the base of the sigmoid colon, thus achieving intestinal obstruction by bifocal strangulation of the sigmoid and ileum [1].

The etiology of this pathology remains unclear. In the literature dolichocolon, meso hyperplasia, lengthening and proximity of the feet to the sigmoid loop and also distension of the anterior abdominal wall are the main anatomical factors implicated. Post-surgical adhesions, internal hernias, Meckel's diverticulum and malrotations of the primary intestinal loop could also be contributing factors [2].

The ileosigmoid node is a medico-surgical emergency that represents a rare cause of acute intestinal obstruction [2]. Delay in diagnosis often leads to complications with a consequent high incidence of digestive necrosis. In $56 \%$ of cases, it progresses to hypovolemic shock [2]. Its treatment is mainly surgical and mortality is high, and the prognosis is severe. It was first described by PARKER in 1845 . The ileosigmoid node is a rare entity.

In parts of Asia there was $7.6 \%$ of all sigmoid colon volvulus according to altamanalp. [2]. In France there was (less than 1\%) of all sigmoid volvulus, according to C. Journé [3].

In Niger, the ileosigmoid node represents $4.6 \%$ of all sigmoid volvuli, according to James Didier [4].

In Mali at the CHU GT there was $1.66 \%$ of all mechanical intestinal obstruction according to a study by M. Konaté et al. [5]. In Sikasso there was $7.40 \%$ of all sigmoid volvulus according to Dembélé C. [6].

\section{Objective}

To determine the frequency of NIS, to describe the diagnostic aspects, therapeutic aspects and to analyze the postoperative effects.

\section{Methodology}

Retrospective and prospective study from January 2006 to December 2020; including all patients operated on for ileosigmoid node confirmed by the intraoperative diagnosis at the CHU Gabriel Touré.

\section{Results}

From January 2006 to December 2020 (15 years), we recorded 30 cases of ileo node in the service. This represented $0.19 \%(30 / 15,304)$ of surgeries, $0.34 \%$ (30/8782) of abdominal emergencies, 2.62\% (30/1145) of bowel obstructions, $6.84 \%$ (30/438) intestinal volvulus. The average age was $44.8 \pm 15$ years with the extremes of 21 years and 75 years. The standard deviation was 15 (Figure 1). The male sex was the most represented, ie $83 \%$ of cases with a sex ratio $=5$ (Figure 2). Abdominal pain was present in (100\%) of cases, vomiting was present in $80 \%$ and cessation of materials and gas (57\%) (Table 1). The abdominal $\mathrm{x}$-ray without preparation was carried out in 30 patients, i.e. $100 \%$ and 


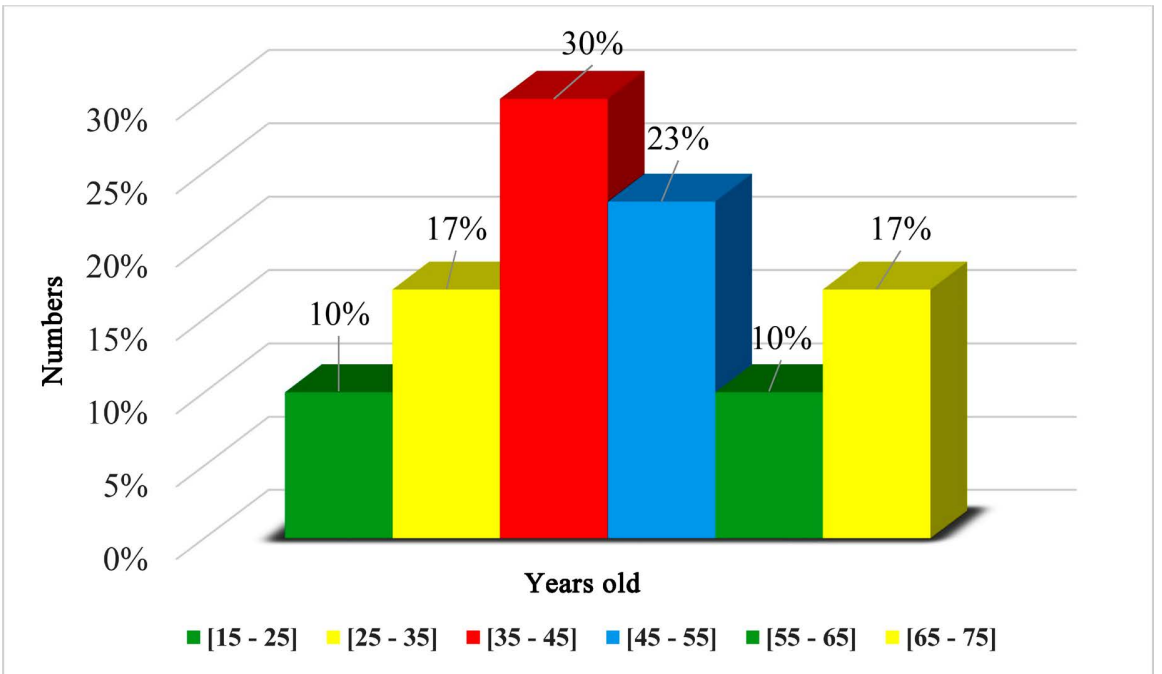

Figure 1. The age group.

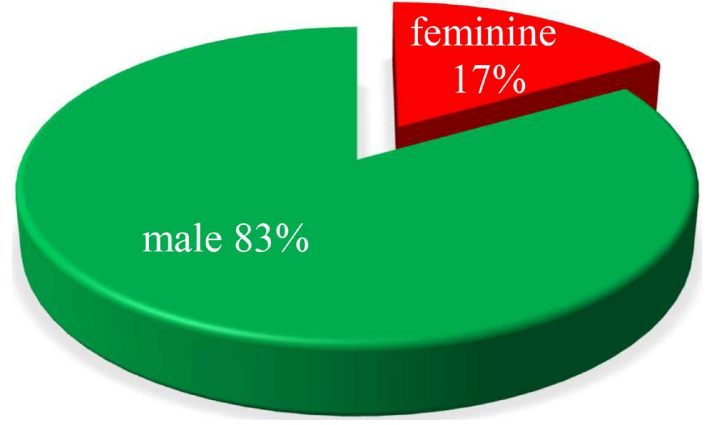

Figure 2. Their sexes.

Table 1. Signes fonctionnels.

\begin{tabular}{ccc}
\hline signes fonctionnels & Effective & Percentage \\
\hline Abdominal pain + Vomiting + Material and gas shutdown & 17 & $57 \%$ \\
Abdominal pain & 5 & $100 \%$ \\
Abdominal pain + Vomiting & 24 & $80 \%$ \\
\hline
\end{tabular}

Table 2. The results of the $\mathrm{x}$-ray of the abdomen without preparation.

\begin{tabular}{ccc}
\hline ASP & Effective & Percentage \\
\hline Double jamb & 19 & $63 \%$ \\
Central levels & 3 & $10 \%$ \\
Peripheral levels & 6 & $20 \%$ \\
Mixed levels & 2 & $7 \%$ \\
Total & 30 & $100 \%$ \\
\hline
\end{tabular}

showed a double leg in $63 \%$ of cases (Table 2). All our patients were operated on, exploration found intestinal necrosis in $97 \%$ (Table 3). Type I is the most 
encountered in our series, i.e. $60 \%, 27 \%$ of type II and $13 \%$ of type III. On the other hand, we have not identified type 4 (Figure 3 ). The surgical procedures performed were colostomy according to HARTMANN (63\%), anastomosis resection (16\%), devolvulation (10\%) (Table 4). The postoperative consequences were straightforward in (80\%). Morbidity was $17 \%$. Mortality was $3 \%$.

\section{Comments}

The ileosigmoid node is a rare entity of the volvulus, our frequency of $6.84 \%$ (30/438) of intestinal volvulus is without statistically significant difference with Didier Niger [4], and Altamanalp in India [2]. In our series, the male gender predominates. This predominance is reported in several other studies (James Didier 2017, Shephead 1967) [4]. This male predominance could be explained by the fact that men have a very high meso colon and a small pelvis while women have a pelvis. broad and musculature less toned than that of men which allows

Table 3. Condition of handles.

\begin{tabular}{ccc}
\hline Condition of handles & Effective & Percentage \\
\hline Sigmoid necrosis + Ileum necrosis & 22 & $73 \%$ \\
Sigmoid necrosis + viable ileum & 4 & $13 \%$ \\
Viable Sigmoid + viable ileum & 1 & $3 \%$ \\
Viable Sigmoid + Ileum necrosis & 3 & $10 \%$ \\
Total & 30 & $100 \%$
\end{tabular}

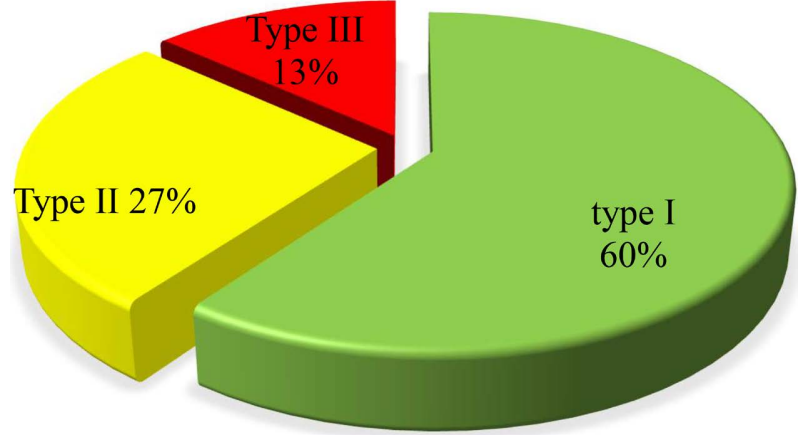

Figure 3. The classification of the ileosigmoid node.

Table 4. Intraoperative procedures.

\begin{tabular}{ccc}
\hline Intraoperative procedures & Effective & Percentage \\
\hline colostomy according to Hartmann & 19 & $63 \%$ \\
Dévolvulation & 3 & $10 \%$ \\
Ileostomy + colostomy of Hartmann & 2 & $6 \%$ \\
Jejunostomy & 1 & $3 \%$ \\
Anastomosis resection & 5 & $16 \%$ \\
Total & 30 & $100 \%$ \\
\hline
\end{tabular}


spontaneous devolvulation. But, during pregnancy, they become more exposed with serious occlusive accidents especially during the third trimester, post partum or after pelvic interventions. Abdominal pain has been found in all of our patients. This proportion does not differ from that of Altamanalp in India [2], Didier in Niger [4] and A. traoré in Mali [7]. Stopping materials and gas: this is the key sign of low bowel obstruction, especially in the case of volvulus. Stoppage of materials and gas were found in $57 \%$ of our patients. There is a statistically significant difference with 0.43 from Altamanalp in India, 0.06 from Didier in Niger and 0.001 from A. Traoré in Mali Vomiting: vomiting is early in the volvulus from the ileosigmoid node was found in $80 \%$ of our patients. There is a statistically significant difference with 0.006 from A. Traoré in Mali. There is no statistically significant difference with Altamanalp in India and Didier in Niger. Our study found $63 \%$ resection + digestive stoma, $16 \%$ underwent immediate anastomosis resection. There is a statistically significant difference with that of Didier in Niger [4]. Our mortality was 3\% and differs statistically from that of Altamanalp [2] in India and Didier in Niger [4].

\section{Conclusion}

The ileosigmoid node is a medico-surgical emergency. The HARTMANN procedure is the most performed followed by one-step anastomosis resection.

\section{Conflicts of Interest}

The authors declare no conflicts of interest regarding the publication of this paper.

\section{References}

[1] Arthur, V., Pascal, A., Hubert, R., et al. (2007) Le noeud ileosigmoidien: Une cause improbable d'occlusion intestinale primitive par strangulationbifocal. Gastroentérologie Clinique et Biologique, 31, 975-977. https://doi.org/10.1016/S0399-8320(07)78308-2

[2] Atamanalp, S.S., Oren, D., Yildirgan, M., et al. (2004) Ileosigmoidal Knotting: Outcome in 63 Patients. Diseases of the Colon \& Rectum, 47, 906-910. https://doi.org/10.1007/s10350-004-0528-9

[3] Journé, C., Ravard, C., Monneuse, O. and Pilleul, F. (2008) Noeud iléosigmoïdien: Une urgence chirurgicale. Journal of Radiology, 89, 1947-1949.

https://doi.org/10.1016/S0221-0363(08)74793-0

[4] Sani, R., Didier, J.L., Chaibou, M.S., et al. (2011) Urgences coliques chirurgicales de l'adulte à l'hôpital national de Niamey (Niger). Journal Africain de Chirurgie Digestive, 11, 1162-1166.

[5] Konaté, M., Traoré, A.A., Koné, T., Karembé, B., Kanté, D., Diop, T.M., et al. (2018) Volvulus du grêle chez l'adulte en Chirurgie Générale au CHU Gabriel Touré, Bamako, Mali. Journal Africain de Chirurgie Digestive, 18, 2307-2311.

[6] Dembele, C. (2014) Volvulus du sigmoide dans le service de chiorurgie Générale de l'hopitale de Sikasso. These de médecine, Bamako, N61, 99.

[7] Traore, H. (2012) Volvulus du sigmoïde dans le service de chirurgie "A" au CHU du point G. Thèse de médecine, Bamako, $\mathrm{N}^{\circ} 60,91$. 